Gmelins Handbuch der anorganischen Chemie

Achte völlig neu bearbeitete Auflage. Herausgegeben von der deutschen chemischen Gesellschaft. Bearbeitet von R. J. Meyer. System-Nummer 53 : Molybdän. Pp. xviii $+x i+393$. (Berlin : Verlag Chemie G.m.b.H., 1935.) 64 gold marks.

MolybDenum was first isolated in 1778 by Scheele, who converted the sulphide into molybdic anhydride, which was then reduced. Twenty years previously, Cronstedt had demonstrated the difference between the lustrous mineral molybdenite and graphite. It was left to Berzelius to explain the chemical character of the element by establishing the composition of molybdic acid.

In view of the wide variation in the valency of molybdenum, it is rather surprising to find that it gives rise to so few oxides. On the other hand, it yields an exceedingly rich assortment of co-ordination compounds, including the important heteropolybasic acids derived from phosphoric, arsenic, silicic and other acids. These occupy considerable space at the end of the present volume. Apart from the heteropolybasic acids, molybdic acid itself develops a high degree of complexity. The classification by Ullik in 1867 of the molybdates into groups according to the ratio of $\mathrm{MoO}_{3}$ to $\mathrm{R}_{2} \mathrm{O}$, where $\mathrm{R}$ represents a univalent metal, was unsatisfactory since the paramolybdates interrupted the simple sequence. These were first formulated as $3 \mathrm{R}_{2} \mathrm{O} \cdot 7 \mathrm{MoO}_{3}$ but later as $5 \mathrm{R}_{2} \mathrm{O} \cdot 12 \mathrm{MoO}_{3}$ from analysis of the barium and thallium salts.

G. Jander and his colleagues have recently introduced a new system based upon a study of diffusion in acid solutions, which has enabled them to detect the transition from the simple $\mathrm{MoO}_{3}$ to 6-, 12- and even 24-fold aggregates of $\mathrm{MoO}_{3}$ in the presence of gradually increasing hydrogen ion concentration. They have also obtained confirmation of their results from measurements of the absorption of visible and ultra-violet light.

The section on alloys does not include the molybdenum steels, which are incorporated in another volume.

\section{Exposés de biométrie et de statistique biologique}

5: Les associations biologiques au point de vue mathématique. Par Vito Volterra et Umberto d'Ancona. (Actualités scientifiques et industrielles, 243.) Pp. 97. (Paris : Hermann et Cie, 1935.) 20 francs.

THIs book contains a systematic summary of a number of papers published mainly by Volterra. The problems treated may be exemplified by the following. Denote by $N_{1}, N_{2}, N_{3}$ the numbers of organisms of three different species, such that the first is feeding on the second and the second on the third. The authors assume simple intuitive hypotheses concerning the three species: (1) The natural death-rate of the two first of them is constant in time. (2) Besides the natural death-rate, there is for the second and third species a death-rate due to the encounters with individuals of the first or the second species respectively. These are assumed to be proportional to the products $N_{1} N_{2}$ and $N_{2} N_{3}$ respectively. (3) The multiplication rate of the third species is proportional to $K-\lambda N_{3}$, where $K$ and $\lambda$ are positive constants, the negative term being due to the limitation in space occupied by the species. (4) Lastly, the total of the organisms of one species consumed by the others is transformed into flesh, so that the decrease in weight of one species is accompanied by an equal increase of the other. The above hypotheses lead to three linear differential equations in $N$ 's, which are solved and discussed by the authors.

However crude some of the hypotheses may seem, it is extremely interesting to follow their consequences, which are found to be, on the whole, in agreement with observations, for example, of fish catch made by D'Ancona and others. Presumably, after some further test of the theory, the conclusions may find practical applications, for example, in fishing, etc. The book is brilliantly written, as is usual with the work of Volterra.

J. N.

\section{A Class Book of Magnetism and Electricity}

By H. E. Hadley. Pp. $x+512$. (London: Macmillan and Co., Ltd., 1936.) 6s. $6 d$.

From the point of view of the teacher and the student, one can thoroughly recommend this book. It is impossible to proceed far in the study of electricity without clear conceptions of potential and potential difference. The author introduces these terms at an early stage and points out their analogy to the corresponding terms in a gravitational field of force. This is a distinct improvement on the unsatisfactory analogies to hydrostatic phenomena usually employed. The interposition of historical descriptions in the text, although they are of general interest, sometimes leads to considerable breaks in the continuity of the argument. They are therefore, at least in the chapters necessary for examination purposes, relegated to collected historical notes given at the ends of the chapters.

Although primarily intended for school certificate and matriculation examinations, this book will be found useful to all desirous of obtaining accurate knowledge about the extensive and ever increasing practical applications of electrical science. It is clearly printed and easy to read, and contains no less than 432 diagrams, many of which are novel and instructive.

\section{Topographical Anatomy of the Dog}

By Dr. O. Charnock Bradley. Third edition. Pp. xii +284. (Edinburgh and London: Oliver and Boyd, 1935.) 25s. net.

THE number of books dealing with the anatomy of the dog is strikingly small. This third edition of the topographical anatomy is a credit to the distinguished principal of the Royal Dick Veterinary College. The instructions for dissection together with the ninety. one illustrations make the book invaluable to the zoologist, physiologist and comparative anatomist.

It is to be hoped that the author will write a short book dealing with the growth of that animal which is the "friend of all our friendships and foeman of our foes". 